\title{
Weak interactions between water and clathrate-forming gases at low pressures
}

\author{
Konrad Thürmer ${ }^{a,{ }^{*}}$, Chunqing Yuan ${ }^{b}$, Greg A. Kimmel ${ }^{b}$, Bruce D. Kay ${ }^{b}$, and R. Scott Smith ${ }^{b}$ \\ ${ }^{a}$ Sandia National Laboratories, Livermore, California 94550, USA \\ ${ }^{\mathrm{b}}$ Fundamental \& Computational Sciences Directorate, Pacific Northwest National Laboratory, \\ P.O. Box 999, Richland, Washington 99352, USA
}

Using scanning probe microscopy and temperature programed desorption we examined the interaction between water and two common clathrate-forming gases, methane and isobutane, at low temperature and low pressure. Water co-deposited with up to $10^{-1} \mathrm{mbar}$ methane or $10^{-5} \mathrm{mbar}$ isobutane at $140 \mathrm{~K}$ onto a $\mathrm{Pt}(111)$ substrate yielded pure crystalline ice, i.e., the exposure to up to $\sim 10^{7}$ gas molecules for each deposited water molecule did not have any detectable effect on the growing films. Exposing metastable, less than 2 molecular layers thick, water films to $10^{-5}$ mbar methane does not alter their morphology, suggesting that the presence of the $\mathrm{Pt}(111)$ surface is not a strong driver for hydrate formation. This weak water-gas interaction at low pressures is supported by our thermal desorption measurements from amorphous solid water and crystalline ice where $1 \mathrm{ML}$ of methane desorbs near $\sim 43 \mathrm{~K}$ and isobutane desorbs near $\sim 100 \mathrm{~K}$. Similar desorption temperatures were observed for desorption from amorphous solid water.

Keywords: Clathrates; Water; Methane; Isobutane; STM; TPD

\footnotetext{
* Corresponding author at: Sandia National Laboratories, Livermore, California 94550, USA. . E-mail address: kthurme@ sandia.gov (K. Thürmer), Tel.: +1 9252944564
} 


\section{Introduction}

Owing to their large natural abundance(s), often at the same location, the interaction between hydrocarbons and water plays an important role in various geochemical and astrochemical settings. Most importantly, some gaseous hydrocarbons like methane combine at low temperatures and elevated pressures with water to form clathrates, i.e., solid hydrates consisting of individual gas molecules surrounded by cages of hydrogen-bonded water molecules [1]. Clathrate deposits have been found in large quantities on the outer continental shelf and in permafrost environments $[1,2,3]$ and are believed to occur in numerous astrophysical environments $[4,5,6,7]$. The prospect of exploiting them as energy sources but also incidents of pipeline blockages by clathrates and the danger from potential releases of large quantities of methane, a potent greenhouse gas, have fueled extensive research aimed at understanding the interaction between water and hydrate-forming natural gases (henceforth "HFNG"). Various research groups have synthesized natural gas clathrates under laboratory conditions that mimic geological $[1,8,9,10,11]$ or astrophysical $[5,6,12,13,14]$ environments yielding valuable information about thermal properties and bulk phase equilibria.

However, experiments that probe molecular-level amounts of material $[15,16,17]$ are scarce, and microscopy data are only available down to the micron scale $[9,14]$, Thus, there is little direct experimental support for modeling efforts $[18,19,20,21,22,23,24]$ to understand how HFNGs interact with water at the molecular scale. Under conditions at which natural clathrates are typically found on earth, i.e., temperatures between $250 \mathrm{~K}$ and $300 \mathrm{~K}$ and pressures on the order of 100 bar [1,25], hydrate formation occurs much too fast to be observable with molecularlayer resolution. To achieve such sensitivity, experiments must be conducted at much lower pressure and temperature. In this work we employ an ultrahigh vacuum (UHV) environment to control the amount of examined material with molecular-layer accuracy. We deposit water and HFNGs onto an atomically flat $\operatorname{Pt}(111)$ substrate and monitor their interaction using two surface science techniques with sub-molecular layer resolution, scanning tunneling microscopy (STM) and temperature programmed desorption (TPD).

The experimental conditions are chosen with two goals in mind. The first is to increase the likelihood of forming clathrates or precursors thereof, or at least, get as close as possible to clathrate stability, by reducing temperature and increasing gas pressure. The second goal is to adjust the thermal mobility of water molecules such that mass transport involving crystalline ice or clathrates occurs at a rate that permits molecular-layer resolved monitoring. For water molecules, in order to arrange themselves into ordered structures, i.e., the crystal lattice of ice or hydrate cages, they have to be able to break and reform hydrogen bonds at a sufficient rate. Judging from measured rates of bulk diffusion [26] and surface diffusion [27] of ice, the lowest temperature at which formation of crystalline clathrates is expected to occur at a convenient time scale is $\approx 140 \mathrm{~K}$. We thus deposit the films for our STM experiments at $\approx 140 \mathrm{~K}$. 
We chose methane for our study because it is by far the most abundant clathrate-forming hydrocarbon. Isobutane was selected because it is also rather common, accounting for $\approx 1 \%$ of the clathrates found in the earth's oceans, and because its hydrate requires a significantly lower pressure to be stabilized than methane clathrate [1]. Perhaps due to a recent focus mostly on terrestrial hydrates, there are only few data available for the methane/water system below $230 \mathrm{~K}$, and, apparently none for isobutane/water. Fray et al. [6] compiled an equilibrium-pressure curve of methane clathrate as a function of temperature based on their own measurements and those of Delsemme and Wenger [5], Falabella and Vanpee [12], and others. Extrapolating this curve to $\mathrm{T}=140 \mathrm{~K}$ suggests that a methane pressure of $\approx 15 \mathrm{mbar}$ is needed to stabilize the bulk phase of methane clathrate. According to Sloan et al.'s compiled data presented in Ref. [1], the hydrateforming pressure at the lowest temperature for which data are available is $\sim 50$ times lower for isobutane $(\sim 0.18$ bar at $242 \mathrm{~K},[1,28])$ than for methane $(\sim 9$ bar at $242 \mathrm{~K})$. If this pressure ratio is similar at $\mathrm{T}=140 \mathrm{~K}$, the optimum temperature for our UHV experiments, one would need $\approx 0.3$ mbar of isobutane to stabilize the bulk hydrate phase, a pressure that is still excessively high for operating UHV setups.

However, at these low temperatures, clathrates might be able to exist also outside their bulkstability region as a metastable bulk phase (like amorphous solid water that persists, or cubic ice that persists and even forms at $140 \mathrm{~K}[29,30])$. In addition, clathrates might have an extended stability region near interfaces, the same way as, for example, water pentagon-hexagon-heptagon arrangements represent the equilibrium configuration in the $2 \mathrm{D}$ wetting layer of water on $\mathrm{Pt}(111)$ [31,32], $\mathrm{Ni}(111)$ [33], $\mathrm{Pd}(111)$, and $\mathrm{Ru}(0001)$ [34], despite not being stable in the bulk at any pressure or temperature. That interfaces could promote the formation of methane clathrates had recently been suggested by Pirzadeh and Kusalik [24] for the case of an ice-solution interface.

Guided by the considerations above we explored various kinetic pathways to promote a strong HFNG-water interaction. Besides co-deposition of water with methane or isobutane, we also grew HFNG and water layers sequentially followed by annealing to $\approx 140 \mathrm{~K}$. Most experiments resulted in ice layers without clear evidence that the presence of the HFNGs had any effect on film structure and morphology. However, when first growing a saturated isobutane monolayer followed by 2-3 molecular layers of water, a film with smooth and clustered regions developed. This morphology, very distinct from that of pure water films, could either indicate formation of a 2D hydrate layer or be the result of water dewetting facilitated by the presence of isobutane.

\section{Experimental methods}

\subsection{Scanning tunneling microscopy experiments}

For the STM experiments, we prepared and analyzed the film samples in a UHV chamber with a base pressure of $<3 \times 10^{-11}$ mbar. Water was deposited at a rate of $\approx 1 \AA / \mathrm{min}$ by directing water vapor onto an atomically flat $\mathrm{Pt}(111)$ surface held at $140 \mathrm{~K}$. For gas exposure the UHV 
chamber was backfilled using standard UHV leak valves. During most co-deposition experiments the water deposition rate was maintained by monitoring the $\mathrm{m} / \mathrm{z}=18$ peak with a mass spectrometer, while gas exposure was controlled with an ion gauge measuring the total chamber pressure. During film growth, the STM tip was retracted far from the sample to exclude tip-induced modifications of the films. STM measurements were performed at $\mathrm{T}<110 \mathrm{~K}$ using tunnel currents below $1 \mathrm{pA}$. To image films thicker than $1 \mathrm{~nm}$ non-destructively [35,36] we applied a sample bias of $\approx-6 \mathrm{~V}$.

For gas exposures above $10^{-5}$ mbar all high voltages in the UHV chamber, including ion gauge and mass spectrometer, were turned off. The integrity of the vacuum was maintained by two turbo pumps operating through partially closed valves. The chamber pressure, between $10^{-3}$ and 1 mbar, was measured with a convectron gauge calibrated for methane, and above 1 mbar, a Heise pressure transducer was used. Condensation of significant amounts of gas onto the coldest parts in the UHV chamber ultimately limited the maximum gas pressures we could apply. In the case of methane, release of condensation heat and possibly increased heat loss via thermal conduction through the methane gas limited the maximum methane pressure to $0.1 \mathrm{mbar}$. At higher pressures the sample temperature and the methane pressure could not be controlled simultaneously. In the case of isobutane, the maximum pressure for well-controlled experiments was $\sim 10^{-5}$ mbar. At higher pressures, significant amounts of isobutane desorbed from cold surfaces of the cooling system and re-adsorbed on the sample surface when cooling the sample below $110 \mathrm{~K}$ for STM measurements.

\subsection{Thermal desorption experiments}

The TPD experiments were conducted at PNNL in a UHV chamber with a base pressure of $<1 \times 10^{-10}$ mbar which has been described in detail elsewhere. [37,38] Briefly, the substrate was a $1 \mathrm{~cm}$ diameter by $1 \mathrm{~mm}$ thick $\mathrm{Pt}(111)$ single crystal that was spot-welded on the back side to tantalum leads for resistive heating. A K-type thermocouple spot-welded to the back of the $\operatorname{Pt}(111)$ substrate was used to measure temperature with a precision of better than $\pm 0.01 \mathrm{~K}$ and an estimated absolute accuracy of $\pm 2 \mathrm{~K}$. The $\mathrm{Pt}(111)$ was cleaned using $\mathrm{Ne}^{+}$sputtering, oxygen anneal, and temperature annealing previously described. [38] The substrate was cooled using a closed cycle helium cryostat that could achieve a base temperature of $\sim 25 \mathrm{~K}$.

Water films were deposited using a quasi-effusive molecular beam collimated by three stages of differential pumping at normal incidence to the $\operatorname{Pt}(111)$ substrate. Water was deposited at a rate of $0.87 \mathrm{ML} / \mathrm{s}$, where $1 \mathrm{ML}$ is defined as the monolayer saturation coverage on the $\mathrm{Pt}(111)$ substrate and corresponds to $\sim 1.1 \times 10^{15}$ molecules $/ \mathrm{cm}^{2}$. [39] The HFNG's were deposited at normal incidence using a separate quasi-effusive molecular beam collimated by four stages of differential pumping. The coverages of the HFNG's were defined by their monolayer saturation coverages on $\mathrm{Pt}(111)$. The $\mathrm{ML}$ areal coverage $\left(\# / \mathrm{cm}^{2}\right)$ can be estimated by converting the liquid density $\left(0.422 \mathrm{~g} / \mathrm{cm}^{3}\right.$ for $\mathrm{CH}_{4}$ and $0.594 \mathrm{~g} / \mathrm{cm}^{3}$ for isobutane) to a number density (molecules $/ \mathrm{cm}^{3}$ ) and taking the $2 / 3$ root. This procedure yields a ML density of 
$6.3 \times 10^{14}$ molecules $/ \mathrm{cm}^{2}$ for methane and $3.4 \times 10^{14}$ molecules $/ \mathrm{cm}^{2}$ for isobutane. The desorption spectra were obtained with an Extrel quadrupole mass spectrometer in a line-of-sight configuration. Methane desorption was monitored at $\mathrm{m} / \mathrm{z}=15$ and $\mathrm{m} / \mathrm{z}=43$ was utilized for isobutane desorption. A linear heating rate of $1 \mathrm{~K} / \mathrm{s}$ was used for all of the TPD experiments.

\section{Results and discussion}

3.1. The interaction of water and methane

\subsubsection{Co-deposition of water and methane}

The first experiment to probe water-methane interaction was performed via co-deposition of water and methane onto a well-cleaned $\mathrm{Pt}(111)$ single-crystal substrate held at $140 \mathrm{~K}$. The sample surface was simultaneously exposed for 8 min to $p_{\text {water }}=5 \times 10^{-9}$ mbar partial pressure of water and a partial pressure of $\mathrm{p}_{\text {meth }}=10^{-5} \mathrm{mbar}$ methane. The choice of $\mathrm{p}_{\text {Meth }}=10^{-5} \mathrm{mbar}$ is dictated by the maximum pressure at which water deposition could be controlled precisely (via mass spectrometer) and the integrity of the ultrahigh vacuum could be fully maintained (via a turbo pump). Except for the added exposure to methane all experimental conditions, i.e., sample temperature, partial pressure of water, and exposure time were chosen to match those that had previously [35,36] been used to grow 2-3 nm high crystallites of ice $\mathrm{I}_{\mathrm{h}}$ embedded in a 1-molecule thin wetting layer. Fig. 1(a) shows the unambiguous result: a film evolved that is indistinguishable from ice films grown in the absence of methane. (For comparison see Fig. 3 (c) in Ref. [35] and Fig. 1 in [36]). From this close match in morphology we infer that the film grown via co-deposition also consists of pure water ice and not hydrate. This inference is based on the common observation that film morphologies, e.g., the aspect ratio of crystals, are very sensitive to changes in energetic and kinetic parameters. For example, small variations in growth conditions of water/Pt(111) (compare Refs. [40] and [41] with Refs. [36] and [42]), or substituting the $\operatorname{Pt}(111)$ substrate with $\mathrm{Ni}(111)$ [33] lead to dramatic changes in film morphology, i.e., the aspect ratio of isolated crystallites and the mean film thickness at coalescence. We thus assume that substituting water ice with gas hydrate as the film material would result in an obvious change in morphology, inconsistent with what we observe.

For the following co-deposition experiment we increased the methane pressure to the maximum value $\mathrm{p}_{\text {meth }}=0.1 \mathrm{mbar}$ at which both, the sample temperature and the methane pressure could still be reasonably well controlled. (Condensation of methane onto the cooling assembly caused the sample to heat up, which had to be compensated by increasing the flow of the liquid He cooling fluid. Resulting variations in methane condensation led to methane pressure changes, which then had to be compensated by adjusting the methane dose.) The temperature excursions were smaller than $\pm 5 \mathrm{~K}$, and the methane pressure was maintained with an accuracy of $\sim 50 \%$. In this experiment we deposited water for a longer time, $15 \mathrm{~min}$, to reduce the relative impact of the inaccuracy of the deposition amounts during the initial phase of co- 
deposition. ${ }^{1}$ After co-depositing water at $\mathrm{p}_{\text {water }}=5 \times 10^{-9}$ mbar and methane at $\mathrm{p}_{\text {meth }}=0.1 \mathrm{mbar}$ for $\approx 15$ min onto the Pt sample held at $140 \mathrm{~K}$, water dosing was stopped while exposure to $0.1 \mathrm{mbar}$ methane was continued for 5 more min before the sample was cooled down for imaging.

The resulting film is depicted in Fig. 1 (b) and at higher magnification in Fig. 1(c). This snake-like morphology is characteristic of the early stage of coalescence during the growth of crystalline ice films. The morphology is strikingly similar to that of an ice film grown under similar conditions but without methane, shown in Fig. 3(d) of Ref. [35]. There are two differences, though. First, the lateral scale of the features in the co-deposited film are smaller, presumably due to reduced water diffusion, which might have been caused by a slightly lower sample temperature or by the presence of the methane. The second difference from the pure water experiment in Ref. [35] is that the film surface is not molecularly flat. The slightly rounded shapes in Fig. 1 (b,c) are most certainly produced by 'post-growth' residual material that adsorbed onto the film after quenching the sample to the imaging temperature, because the chamber pressure recovered only very slowly from dosing methane at 0.1 mbar. (Three hours after film deposition the chamber pressure was still $4 \times 10^{-4}$ mbar). But the average height of the crystallites at coalescence, a value very sensitive to surface, interface, and surface-step energies, and therefore highly dependent on the film material, is identical $(\approx 2 \mathrm{~nm})$ within experimental error. As in the previous experiment discussed above, this close match in morphology leads us to infer that the film grown via co-deposition also consists of pure water ice and not hydrate. Thus, the simultaneous exposure to approximately $\mathbf{1 0}^{7}$ methane molecules for each deposited water molecule has no obvious effect on the formation of an ice film, except, possibly, a small reduction in water surface diffusion!

\subsubsection{Sequential deposition of water and methane}

To probe whether the presence of the $\mathrm{Pt}(111)$ substrate enhances the water-methane interaction, very thin metastable water films were subjected to methane exposure. First a water film of $\approx 2$ molecular layers (ML) thickness was grown by exposing the $\mathrm{Pt}(111)$ surface held at $145 \mathrm{~K}$ to $2 \times 10^{-9}$ mbar water for $90 \mathrm{~s}$. The resulting film, shown in Fig. 2 (a), is comprised of 2 to $3 \mathrm{ML}$ thick patches (bright) embedded in a $1 \mathrm{ML}$ thick wetting layer (black). This configuration is metastable because a water film of the same thickness in equilibrium consists of much taller 3D crystallites embedded in a 1 ML-thick wetting layer [43,35]. Exposing this configuration to $10^{-5}$ mbar methane does not cause any discernable change in the film morphology (Fig. 2(b)), revealing that the close proximity of the interface with the $\mathrm{Pt}(111)$ crystal does not tip the phase balance towards hydrate formation. A similar experiment was performed by first growing a

1 The co-deposition experiment with $\mathrm{p}_{\text {meth }}=0.1$ mbar required an initialization period of $\approx 5 \mathrm{~min}$ during which stable pumping and water and methane dosing had to be established: First, water dosing was initialized and deemed stabilized when the mass spectrometer signal of $\mathrm{p}_{\text {water }}$ varied by less than $\approx 10 \% / \mathrm{min}$ without regulating the water dosing valve. Then, the ion gauge and mass spectrometer were shut off and the methane exposure was ramped up to $0.1 \mathrm{mbar}$, simultaneously adjusting the sample cooling to maintain a sample temperature of $140 \mathrm{~K} \pm 5 \mathrm{~K}$. 
$1 \mathrm{~nm}$ thick metastable amorphous solid water (ASW, "amorphous ice") film at $110 \mathrm{~K}$, and subsequently annealing this film in a methane atmosphere of $10^{-7}$ mbar at $145 \mathrm{~K}$ for $10 \mathrm{~min}$. Again, exposure to methane did not cause any detectable change in film morphology (not shown).

\subsubsection{Thermal desorption experiments of the water/methane system}

The above STM experiments clearly show that neither the co- nor sequential deposition of methane has an effect on the morphology of vapor deposited water films. These results suggest that the methane-water interaction is too weak to affect changes in the water structure. To gain quantitative insight into the energetics of the methane-water interaction we now examine how a ML of methane desorbs from water substrates (for TPD measurements involving higher methane coverages see supplementary material S1). Figure 3 displays the TPD spectra for $1 \mathrm{ML}$ of methane deposited on a 100 ML thick ASW film (red curve), on a 100 ML thick crystalline ice (CI) film (blue curve), and on bare $\operatorname{Pt}(111)$ (green curve). The ASW film was initially deposited at $30 \mathrm{~K}$ and then heated to $80 \mathrm{~K}$ to remove some of the film's surface microporosity.[38] The spectra show that methane on either ASW or CI desorbs at a much lower temperature than on $\mathrm{Pt}(111)$ but the difference between ASW and CI is small. A rough estimate of the binding energy can be obtained from the Polanyi-Wigner equation [44] using the peak temperature, peak desorption rate, peak coverage, and assuming first-order desorption kinetics. A prefactor of $10^{13} \mathrm{~s}^{-1}$ has been experimentally determined for methane desorption from $\mathrm{MgO}(100)$, $\mathrm{C}(0001) / \mathrm{Pt}(111)$, and $\mathrm{Pt}(111)$ [45] and was used in the calculations for methane. This calculation yields binding energies of $11.0,11.2$, and $16.7 \mathrm{~kJ} / \mathrm{mol}$ for methane on ASW, CI, and $\mathrm{Pt}(111)$ respectively. It is interesting to note that the methane binding energies on ASW and CI are much lower than the hydrogen bond energy of $29.5 \mathrm{~kJ} / \mathrm{mole}$ in crystalline ice [46] and the sublimation energy of $\sim 55 \mathrm{~kJ} / \mathrm{mol}$ for multilayer ASW and crystalline ice. [47] These results are consistent with the STM observations that methane does not affect the ice layer structure. Obviously, a more rigorous analysis is needed to obtain more accurate binding energies, but these estimates do provide a qualitative basis for comparison.

Experiments where methane was deposited underneath of ASW overlayers were also conducted. An example is displayed in Figure 4(a) where 25 ML ASW was deposited on top of $1 \mathrm{ML}$ of methane at $30 \mathrm{~K}$. The methane desorption (black curve) is delayed until about $159 \mathrm{~K}$ and occurs at a "bump" in the water desorption spectrum (blue curve). The "bump" is the result of the higher free energy (higher vapor pressure) amorphous phase transforming to the lower free energy (lower vapor pressure) crystalline phase. The abrupt desorption of the gas underlayer during crystallization of ASW has been observed before and has been called the "molecular volcano". [48,16] The abrupt desorption of gases from underneath of ASW films is caused by cracks that form during the crystallization of the ASW overlayer. Figure 4(b) displays TPD spectra for $1 \mathrm{ML}$ of methane underneath of ASW overlayers of 25, 50, 100, and $200 \mathrm{ML}$. The corresponding water spectra are left off here for clarity but are shown in the supplementary 
material as Figure S2. There are two sets of peaks, those between 155-160 K labeled "volcano peaks" and those between 170-185 K labeled "trapped peaks". Crystallization-induced crack formation begins at the vacuum interface and moves into the film and as a result the "volcano" peak moves to higher temperature with increasing overlayer thickness. [16,49,17] At some thickness the cracks do not span the entire film and the underlying methane remains "trapped" in the film until the water overlayer itself desorbs. The amount of methane that desorbs in the "volcano" peak is nearly $100 \%$ for the smallest overlayer thickness (25 ML) but then decreases with increasing overlayer thickness. The temperature for crystallization of the entire film is a function of film thickness and is complete at a temperature just after the volcano peak. Methane that does not desorb in the "volcano" peak remains trapped in the crystallized water film and desorbs when the water layer itself desorbs. For very thick ASW overlayers (> $300 \mathrm{ML}$, not shown) nearly $100 \%$ of the methane desorption occurs in a "trapped" peak. The observations here are the same as those for other gases $\left(\mathrm{N}_{2}, \mathrm{O}_{2}, \mathrm{Ar}, \mathrm{Kr}\right.$, Xe, etc.). [16,17,48,49,50] This result also supports the idea that methane does not affect the ASW structure.

\subsection{The interaction of water and isobutane}

\subsubsection{Co-deposition of water and isobutane}

We also investigated the influence of isobutane on the growth of thin water films. Isobutane is a hydrocarbon that forms hydrates at a significantly lower pressure than methane [1]. Xu et al. [51] reported that isobutane, deposited at $\mathrm{T} \leq 140 \mathrm{~K}$ onto $\mathrm{Pt}(111)$, condenses into a 1-molecule thick 2D layer. To facilitate water-isobutane interaction, we first grew such a monolayer of isobutane at $120 \mathrm{~K}$ by exposing the $\mathrm{Pt}(111)$ surface for $2 \mathrm{~min}$ to $5 \times 10^{-8} \mathrm{mbar}$ isobutane. We then raised the sample temperature to $140 \mathrm{~K}$ for an 8 min co-deposition of $5 \times 10^{-9} \mathrm{mbar}$ water and $5 \times 10^{-8}$ mbar isobutane. The parameters of water deposition were chosen such that, in the absence of isobutane, regularly-shaped 3D ice crystals would emerge $[35,36]$. The sample was then cooled down below $120 \mathrm{~K}$ for imaging. The resulting film is shown in Fig. 5 (a): The 2$3 \mathrm{~nm}$ high azimuthally aligned hexagonal prisms exactly match the morphology of 3D ice crystals that form without any exposure to isobutane [35,36]. As in the case of co-deposited methane (see Section 3.1.1) we infer that the film consists of water-ice crystals. In another experiment the isobutane pressure was increased to the maximum value at which well-controlled experiments could still be performed, $10^{-5} \mathrm{mbar}$. (At higher isobutane pressures large quantities of isobutane condense onto the cold surfaces of the cooling assembly generating a substantial isobutane reservoir inside the UHV chamber. Isobutane desorbing from this reservoir can readsorb onto the sample when it is cooled below $120 \mathrm{~K}$ for imaging.) Fig. 5 (b) shows a film grown by $8 \mathrm{~min}$ co-deposition of $5 \times 10^{-9} \mathrm{mbar}$ water and $10^{-5} \mathrm{mbar}$ isobutane. This significant increase of isobutane pressure had no discernable effect on the resulting film. Hence, an isobutane pressure of $10^{-5} \mathrm{mbar}$ turned out to be still too low to produce hydrates, and pure ice crystals formed instead. 


\subsubsection{Sequential deposition of water and isobutane}

To test whether the presence of the $\operatorname{Pt}(111)$ substrate enhances the water-isobutane interaction, we sequentially grew very thin films of both materials on top of each other. The fact that isobutane sticks to $\operatorname{Pt}(111)$ at $140 \mathrm{~K}$ allows us to cap an isobutane monolayer with two molecular layers of water: Guided by $\mathrm{Xu}$ et al. [51] a saturated monolayer of isobutane was grown at $140 \mathrm{~K}$ by exposing the $\mathrm{Pt}(111)$ surface for $2 \mathrm{~min}$ to $5 \times 10^{-8} \mathrm{mbar}$ isobutane. As seen in the STM images in Fig. $6(\mathrm{a}, \mathrm{b})$, isobutane forms a complete layer and does not cluster. (The main features apparent in Fig. 6 (a) are the atomic Pt(111) steps. Zooming into a substrate terrace (Fig. 6 (b) reveals some structure of the isobutane layer, e.g., a STM tip induced hole.) Subsequent deposition at $140 \mathrm{~K}$ of 2-3 molecular layers of water on top of the isobutane led to a morphology that is approximately evenly divided into smooth and clustered regions, shown in Fig. 6 (c). Annealing the sample to $150 \mathrm{~K}$ had no discernable effect.

Are the clustered regions in Fig. 6 (c) composed of clathrates or clathrate precursors? Fig. $6(a, b)$ had already shown that isobutane by itself does not cluster. But could the isobutane have first migrated to the surface and then formed clusters on top of the water? Or does a 2$3 \mathrm{ML}$ thick water film cluster, with or without the help of isobutane? To elucidate these questions a separate experiment was performed in which the order of deposition was reversed.

As shown in Fig. 6 (d), a pure 2-3 ML thick water forms a complete and rather homogeneous film. In other words, in the absence of isobutane, water (of that thickness) does not cluster. Exposing this film to 6 Langmuir $\left(5 \times 10^{-8} \mathrm{mbar}\right.$ for $\left.2 \mathrm{~min}\right)$ of isobutane does not alter the surface (see Fig. 6 (e)), eliminating the possibility of isobutane clustering when located above the water. Hence there are two remaining straight-forward explanations for the clustering in Fig. 6 (c): the presence of the $\operatorname{Pt}(111)$ substrate promotes the formation of a hydrate, or the presence of isobutane facilitates dewetting and clustering of water. Lacking a method with chemical sensitivity, like infrared adsorption spectroscopy (IRAS), the nature of the clusters in Fig. 6 (c) could not be determined with certainty.

\subsubsection{Thermal desorption experiments of the water/isobutane system}

Analogous experiments to those conducted for methane (see Section 3.1.3.) were also performed for isobutane. Figure 7 displays the TPD spectra for 1 ML of isobutane on ASW (red curve), CI (blue curve), and $\operatorname{Pt}(111)$ (green curve). (TPD results involving higher isobutane coverages are documented in Supplementary materials S3.) The desorption peak temperatures of 97.1 K and 98.5 K from CI and ASW are relatively close while desorption from $\mathrm{Pt}(111)$ occurs much higher peaking at $167 \mathrm{~K}$. Using the method described in Section 3.1.3., an estimate of the binding energy was obtained using the Polanyi-Wigner equation. A prefactor of $\sim 10^{15} \mathrm{~s}^{-1}$ had previously been determined experimentally for butane desorption from $\mathrm{MgO}(100)$, $\mathrm{C}(0001) / \mathrm{Pt}(111)$, and $\mathrm{Pt}(111)$ [45] and was used here as a reasonable estimate of the isobutane desorption prefactor. The estimated binding energies were $29.6,27.9$, and $50.3 \mathrm{~kJ} / \mathrm{mol}$ for 
isobutane on $\mathrm{ASW}, \mathrm{CI}$, and $\mathrm{Pt}(111)$ respectively. As was the case for methane, the isobutane binding energies on ASW and CI are lower than the hydrogen bond energy of $29.5 \mathrm{~kJ} / \mathrm{mole}$ in crystalline ice [46] and the multilayer sublimation energy of $\sim 55 \mathrm{~kJ} / \mathrm{mol}$ for ASW and CI. [47]

Figure 8 displays the TPD spectra for $1 \mathrm{ML}$ of isobutane from underneath of ASW overlayers of 25, 50, 100, and $200 \mathrm{ML}$. As described in Section 3.1.3., the peaks from 155 to $165 \mathrm{~K}$ are "volcano" peaks and those above $\sim 165 \mathrm{~K}$ are "trapped" peaks. The overall pattern with increasing ASW thickness is nearly identical to that observed for methane. The overall similarity of the isobutane results with those for methane (Fig. 4(b)) and other gases $[16,17,48,49,50]$ suggests that isobutane does not uniquely change the behavior of the ASW overlayer. That is, we observe no evidence for the formation of isobutane induced clathrate structures.

\section{Conclusions}

Various different kinetic pathways have been explored with the goal of facilitating waterHFNG interaction and tracking the evolution of the water-HFNG samples with molecular-layer precision. At $140 \mathrm{~K}$ and pressures at which gas pressure and sample temperature could be well controlled in our UHV apparatus, methane and isobutane exhibit a remarkably weak interaction with water. Applying up to 0.1 mbar of methane or $10^{-5}$ mbar of isobutane in co-deposition experiments did not produce clathrates, and only led to ice formation. Capping a molecular layer of isobutane with two molecular layers of water might have led to substrate-induced hydrate formation, but the alternative explanation that the presence of isobutane merely facilitated dewetting and clustering of water is at least as likely. In principle, tracking methane clathrate formation with scanning probe microscopy might be possible. But keeping a sample at $\sim 140 \mathrm{~K}$ and simultaneously exposing it to nearly atmospheric pressure methane would pose a serious design challenge for vibration-isolated microscopy setups: the sample has to be cooled without exposing other cold surface areas to water and the hydrate-forming gas.

The TPD results support the idea that the interactions of methane and isobutane with water at the temperature and pressure (UHV) conditions of these experiments do not induce the formation of clathrate structures. Based on the monolayer desorption temperatures of $\sim 43 \mathrm{~K}$ for methane and $\sim 100 \mathrm{~K}$ for isobutane, the estimated adsorbate-water interaction energies are weaker than the water hydrogen bond energy and the multilayer water sublimation energy. These relatively weak HFNG-water interactions lead to rapid desorption of the HFNG at low temperature, making it difficult to maintain a significant HFNG coverage on either ice or ASW at higher temperatures for the HFNG pressures attainable in typical UHV-based surface science experiments. Experiments where the two adsorbates were deposited underneath of water overlayers provided no evidence for clathrate formation. Instead the two gases displayed the familiar "volcano" and "trapped" peak behavior exhibited by many other gases. Overall, the TPD results show that the adsorbate-water interactions are weaker than the water-water interactions, which supports the interpretations of the STM results. One would expect that for 
any adsorbate, regardless of the interaction energy, a minimum contact time and/or a steady-state HFNG coverage at a critical temperature would be required to induce clathrate formation.

For example, it is instructive to estimate the adsorbate coverage for the pressure and temperature conditions of these experiments. The steady-state adsorbate coverage is determined by equating the adsorption and desorption fluxes, $J_{\text {in }} S=k_{\text {Des }} \cdot \theta$, where $J_{\text {in }}$ is the incident flux, $S$ is the sticking coefficient, $k_{D e s}$ is the temperature dependent desorption rate constant, and $\theta$ is the surface coverage. Rearranging this equation and for a sticking coefficient of 1 , the steady-state coverage is given by $\theta_{S S}=J_{i n} / k_{D e s}$. The incident flux on the surface, $J_{i n}$, can be calculated using the equation from gas kinetic theory, $J_{i n}=P /(2 \pi m k T)^{1 / 2}$, where $P$ is the gas pressure, $m$ is the molecular weight, $k$ is the Boltzmann constant, and $T$ is the gas temperature.[52] The desorption flux is given by, $J_{d e s}=k_{D e s} \theta=v \theta \exp (-E / R T)$, where $v$ is the prefactor and $E$ is the adsorbate binding energy. Prefactors for methane and isobutane were $1 \times 10^{13} \mathrm{~s}^{-1}$ and $1 \times 10^{15} \mathrm{~s}^{-1}$, respectively, and the binding energies were those obtained from the 1 ML TPD spectra described in Sections 3.1.3. and 3.2.3. The binding energies for methane on CI $(11.2 \mathrm{~kJ} / \mathrm{mol})$ and for isobutane on CI $(27.9 \mathrm{~kJ} / \mathrm{mol})$ were used. For the methane experimental conditions in Fig. 1 (b,c), a background pressure of $0.10 \mathrm{mbar}$ and a surface temperature of $145 \mathrm{~K}$, the calculated steady-state coverage is $6.6 \times 10^{-5} \mathrm{ML}$. For the isobutane experimental conditions in Fig. 5(b), a background pressure of $1.0 \times 10^{-5} \mathrm{mbar}$ and a surface temperature of $140 \mathrm{~K}$, the steady state coverage is $1.5 \times 10^{-4} \mathrm{ML}$. The extremely low steady-state coverages for the lowpressure conditions of our experiments likely accounts for our inability to observe clathrate formation. One expects that the probability of clathrate formation would increase with the coverage of the HFNG species. In the Introduction we mentioned the observation of clathrate formation at 9 bar for methane and 0.18 bar isobutane at $242 \mathrm{~K}$. For these conditions we estimate a steady-state coverage of $0.14 \mathrm{ML}$ for methane and 0.13 ML for isobutane. One can now calculate the pressure required to achieve these coverages at the temperatures of the STM experiments. To obtain a steady-state coverage of $0.14 \mathrm{ML}$ for methane on CI at $145 \mathrm{~K}$ would require a gas pressure of 213 mbar. Similarly, to obtain a coverage of $0.13 \mathrm{ML}$ of isobutane on $\mathrm{CI}$ at $140 \mathrm{~K}$, a gas pressure of $7.6 \times 10^{-2}$ mbar would be needed. Obviously, to obtain these steady-state coverages requires pressures that are well-above the pressure conditions for UHV systems.

In summary, our STM and TPD experiments show that, at low pressure, methane's and isobutane's interactions with water are extremely weak. At the lowest temperature at which the mobility of water molecules should still suffice for the assembly of clathrate cages, $\sim 140 \mathrm{~K}$, and at the highest gas pressures accessible in our UHV setup, i.e., p peth $=0.10 \mathrm{mbar}$ and $\mathrm{p}_{\text {Isob }}=10^{-5}$ mbar, co-deposition of water with methane or isobutane results in pure ice formation. This observation is consistent with the very low binding energies measured with TPD for methane and isobutane ML on ice, i.e., $11 \mathrm{~kJ} / \mathrm{mol}$ and $\sim 28 \mathrm{~kJ} / \mathrm{mol}$. Apparently, steady-state surface coverages estimated from these binding energies, $\theta_{\text {Meth }}=6.6 \times 10^{-5} \mathrm{ML}$ and 
$\theta_{\mathrm{Isob}}=1.5 \times 10^{-4} \mathrm{ML}$, are too low to drive the re-arrangement of water molecules from an ice lattice into clathrate cages. STM and TPD also found no clear evidence that hydrates formed when gases and water were deposited sequentially.

Our experiments conducted at pressures < 0.1 mbar and temperatures as low as $140 \mathrm{~K}$ (STM experiments) and < $185 \mathrm{~K}$ (methane and isobutane desorption) do not capture the environmental conditions under which clathrates form on earth. Nevertheless they can serve as benchmarks against which realistic geophysical models can be tested. e.g., whether those models are able to reproduce our measured desorption energies. Though absent on earth, the low-pressure/low temperature conditions of our experiments are present in a range of astrophysical settings where the occurrence of clathrates had been suggested, for example, in comets [5,53], on outer planets and their moons $[4,6,7,54]$, and even the polar, permanently-shaded craters on Earth's moon [55].

\section{Acknowledgements}

We gratefully acknowledge the discussions with Laura Stern, Randall Cygan, Margaret Gordon, and Stephanie Teich-McGoldrick. The STM research (KT) was supported by the Laboratory Directed Research and Development program at Sandia National Laboratories. Sandia National Laboratories is a multi-program laboratory managed and operated by Sandia Corporation, a wholly owned subsidiary of Lockheed Martin Corporation, for the U.S. Department of Energy's National Nuclear Security Administration under contract DE-AC0494AL85000. The TPD work (CY, GAK, BDK, and RSS) was supported by the U.S. Department of Energy (DOE), Office of Science, Office of Basic Energy Sciences, Division of Chemical Sciences, Geosciences, and Biosciences. The research was performed using EMSL, a national scientific user facility sponsored by DOE' s Office of Biological and Environmental Research and located at Pacific Northwest National Laboratory, which is operated by Battelle for the DOE.

\section{References}

[1] E.D. Sloan and C. Koh, Clathrate Hydrates of Natural Gases, third ed., CRC Press, Boca Raton, FL, 2008, and references therein.

[2] K.A. Kvenvolden, Organic Geochemistry, 23 (1995) 997.

[3] A. V. Milkov, Earth-Science Reviews 66 (2004) 183.

[4] S. L. Miller, Proc. Nat. Acad. Sci. 47 (1961) 1798.

[5] A. H. Delsemme and A. Wenger, Planetary and Space Science 18 (1970) 709.

[6] N. Fray, U. Marboeuf, O. Brissaud, and B. Schmitt, J. Chem. Eng. Data 55 (2010) 5101.

[7] J.I. Lunine, D.J. Stevenson, Astrophysical Journal Supplement Series, 58 (1985) 493. 
[8] L. A. Stern, S. H. Kirby, and W. B. Durham, Science 273 (1996) 1843.

[9] L. A. Stern, S. H. Kirby, S. Circone, and W. B. Durham, Am. Miner. 89 (2004) 1162.

[10] W. F. Kuhs, D. K. Staykova, and A. N. Salamatin, J. Phys. Chem. B 110 (2006) 13283.

[11] S. R. Davies, K. C. Hester, J. W. Lachance, C. A. Koh, and E. D. Sloan, Chemical Engineering Science 64 (2009) 370.

[12] B. J. Falabella and M. Vanpee, Industrial \& Engineering Chemistry Fundamentals 13 (1974) 228.

[13] A. Falenty, G. Genov, T. C. Hansen, W. F. Kuhs, and A. N. Salamatin, J. Phys. Chem. C 115 (2011) 4022.

[14] A. Falenty, A. N. Salamatin, and W. F. Kuhs, J. Phys. Chem. C 117 (2013) 8443.

[15] Y. K. Kim, S. C. Park, J. H. Kim, C. W. Lee, and H. Kang, Journal of Physical Chemistry C $112(2008) 18104$.

[16] P. Ayotte, R. S. Smith, K. P. Stevenson, Z. Dohnalek, G. A. Kimmel, and B. D. Kay, Journal of Geophysical Research-Planets 106 (2001) 33387.

[17] R. A. May, R. S. Smith, and B. D. Kay, J. Chem. Phys. 138 (2013) 104501.

[18] E. D. Sloan and F. Fleyfel, Aiche Journal 37 (1991) 1281.

[19] R. T. Cygan, S. Guggenheim, and A. F. K. van Groos, J. Phys. Chem. B 108 (2004) 15141.

[20] R. W. Hawtin, D. Quigley, and P. M. Rodger, Phys. Chem. Chem. Phys. 10 (2008) 4853.

[21] G. J. Guo, M. Li, Y. G. Zhang, and C. H. Wu, Phys. Chem. Chem. Phys. 11 (2009) 10427.

[22] B. C. Knott, V. Molinero, M. F. Doherty, and B. Peters, J. Am. Chem. Soc. 134 (2012) 19544.

[23] S. A. Bagherzadeh, P. Englezos, S. Alavi, and J. A. Ripmeester, J. Phys. Chem. B 116 (2012) 3188 .

[24] P. Pirzadeh and P. G. Kusalik, J. Am. Chem. Soc. 135 (2013) 7278.

[25] K.A. Kvenvolden, Reviews of Geophysics, 31 (1993) 173-187.

[26] D. E. Brown and S. M. George, J. Phys. Chem. 100 (1996) 15460.

[27] S. Nie, N. C. Bartelt, and K. Thürmer, Phys. Rev. Lett. 102 (2009) 136101.

[28] G. D. Holder and S. P. Godbole, AIChE J. 28 (1982) 930.

[29] P.V. Hobbs, Ice Physics, Clarendon Press, Oxford, 1974.

[30] K. Thürmer, S. Nie, Proc. Nat. Acad. Sci., 110 (2013) 11757-11762.

[31] S. Nie, P. J. Feibelman, N. C. Bartelt and K. Thürmer, Phys. Rev. Lett. 105 (2010) 026102.

[32] S. Standop, M. Morgenstern, T. Michely and C. Busse, J. Phys.-Condes. Matter 24 (2012)

124103.

[33] K. Thürmer, S. Nie, P. J. Feibelman, and N. C. Bartelt, J. Chem. Phys. 141 (2014) 18 C520.

[34] S. Maier, I. Stass, T. Mitsui, P. J. Feibelman, K. Thürmer and M. Salmeron, Phys. Rev. B 85 (2012) 155434.

[35] K. Thürmer and N. C. Bartelt, Phys. Rev. B 77 (2008) 195425.

[36] K. Thürmer and N. C. Bartelt, Phys. Rev. Lett. 100 (2008) 186101.

[37] R. S. Smith, T. Zubkov, and B. D. Kay, J. Chem. Phys. 124 (2006) 114710.

[38] T. Zubkov, R. S. Smith, T. R. Engstrom, and B. D. Kay, J. Chem. Phys. 127 (2007) 184707.

[39] G. A. Kimmel, K. P. Stevenson, Z. Dohnalek, R. S. Smith, and B. D. Kay, J. Chem. Phys.

114 (2001) 5284. 
[40] G. Zimbitas, S. Haq, and A. Hodgson, J. Chem. Phys. 123 (2005) 174701.

[41] G. A. Kimmel, N. G. Petrik, Z. Dohnalek, and B. D. Kay, Phys. Rev. Lett. 95 (2005) 166102.

[42] S. Nie, N. C. Bartelt, and K. Thürmer, Phys. Rev. B 84 (2011) 035420.

[43] G. A. Kimmel, N. G. Petrik, Z. Dohnalek and B. D. Kay, J. Chem. Phys. 126 (2007) 114702.

[44] A. M. Dejong and J. W. Niemantsverdriet, Surf. Sci. 233 (1990) 355.

[45] S. L. Tait, Z. Dohnalek, C. T. Campbell and B. D. Kay, J. Chem. Phys. 125 (2006) 234308.

[46] V. F. Petrenko and R. W. Whitworth, Physics of ice, Oxford University Press, Oxford; New York, 1999.

[47] R. S. Smith, J. Matthiesen, J. Knox, and B. D. Kay, J. Phys. Chem. A 115 (2011) 5908.

[48] R. S. Smith, C. Huang, E. K. L. Wong, and B. D. Kay, Phys. Rev. Lett. 79 (1997) 909.

[49] R. A. May, R. S. Smith, and B. D. Kay, J. Phys. Chem. Lett. 3 (2012) 327.

[50] R. A. May, R. S. Smith, and B. D. Kay, J. Chem. Phys. 138 (2013) 104502.

[51] C. Xu, B. E. Koel, and M. T. Paffett, Langmuir 10 (1994) 166.

[52] G. A. Somorjai, Introduction to surface chemistry and catalysis, Wiley, New York, 1994.

[53] U. Marboeuf, O. Mousis, J.M. Petit, B. Schmitt, Astrophys. J., 708 (2010) 812-816.

[54] E. Lellouch, B. Bezard, F.M. Flasar, S. Vinatier, R. Achterberg, C.A. Nixon, G.L. Bjoraker, N. Gorius, Icarus, 231 (2014) 323-337.

[55] N.S. Duxbury, K.H. Nealson, V.E. Romanovsky, J. Geophys. Research-Planets, 106 (2001) 27811-27813. 


\section{Figure captions}

Fig. 1. Co-deposition of water and methane. (a) $800 \mathrm{~nm} \times 800 \mathrm{~nm}$ STM image of Pt(111) after $8 \mathrm{~min}$ simultaneous exposure at $140 \mathrm{~K}$ to $5 \times 10^{-9} \mathrm{mbar}$ water and $10^{-5} \mathrm{mbar}$ of methane. (b,c) STM images of a film grown via 15 min co-deposition of $5 \times 10^{-9}$ mbar water and $0.1 \mathrm{mbar}$ of methane. Fields of view are $1 \mu \mathrm{m}^{2}$ and $500 \mathrm{~nm} \times 800 \mathrm{~nm}$, respectively. None of the images reveal any evidence of clathrate formation; pure water-ice films evolved instead.

Fig. 2. $200 \mathrm{~nm} \times 200 \mathrm{~nm}$ STM images of a metastable 2 ML-thick water/Pt(111) film grown at $145 \mathrm{~K}$ (a) before, and (b) after a $10 \mathrm{~min}$ exposure to $10^{-5} \mathrm{mbar}$ of methane, revealing that exposure to methane did not modify the film.

Fig. 3. TPD spectra for $1 \mathrm{ML}$ of methane deposited on a $100 \mathrm{ML}$ thick ASW film (red curve), on a $100 \mathrm{ML}$ thick crystalline ice film (blue curve), and on bare $\operatorname{Pt}(111)$ (green curve). Methane was deposited at $25 \mathrm{~K}$ and the heating rate was $1 \mathrm{~K} / \mathrm{s}$.

Fig. 4. TPD spectra of $1 \mathrm{ML}$ of methane buried underneath ASW. (a) TPD spectra for $25 \mathrm{ML}$ of water deposited on top of $1 \mathrm{ML}$ of methane at $30 \mathrm{~K}$ and heated at $1 \mathrm{~K} / \mathrm{s}$. The methane desorption (black curve) is delayed until about $159 \mathrm{~K}$ and occurs at a "bump" in the water desorption spectrum (blue curve). The methane signal is multiplied by a factor of 5. (b) TPD spectra for 1 ML of methane deposited underneath of ASW thicknesses of 25 (black), 50 (red), 100 (blue), and $200 \mathrm{ML}$ (green). Methane and water were deposited at $30 \mathrm{~K}$ and the heating rate was $1 \mathrm{~K} / \mathrm{s}$. The peaks between 155 and $165 \mathrm{~K}$ labeled as "volcano peaks" are due to methane desorption that occurs during ASW crystallization. The "volcano" peak shifts to higher temperature with increasing overlayer thickness. The peaks between 170 and $185 \mathrm{~K}$ are labeled as "trapped peaks" and are due to methane desorption that occurs during desorption of the ASW overlayer.

Fig. 5. STM images of films produced by $8 \mathrm{~min}$ co-deposition of $5 \times 10^{-9} \mathrm{mbar}$ water at $140 \mathrm{~K}$ with (a) $5 \times 10^{-8}$ mbar isobutane, and (b) $10^{-5}$ mbar isobutane. The film in (a) was grown onto a previously deposited molecular layer of isobutane.

Fig. 6. Sequential deposition of water and isobutane. (a,b) STM images of a saturated isobutane monolayer deposited onto $\operatorname{Pt}(111)$ at $140 \mathrm{~K}$. The profile at the bottom was taken along the yellow line in (b). (c) STM image of a saturated isobutane monolayer deposited onto Pt(111) at $140 \mathrm{~K}$, subsequently covered up by 2-3 molecular layers of water. (d,e) STM images of (d) 2 ML of water deposited onto $\mathrm{Pt}(111)$ at $140 \mathrm{~K}$, and (e) after the film of (d) has been exposed at $130 \mathrm{~K}$ for $2 \mathrm{~min}$ to $5 \times 10^{-8} \mathrm{mbar}$ of isobutane, subsequently annealed to $140 \mathrm{~K}$. There is no hint that isobutane sticks to the water surface.

Fig. 7. TPD spectra for $1 \mathrm{ML}$ of isobutane deposited on a $100 \mathrm{ML}$ thick ASW film (red curve), on a $100 \mathrm{ML}$ thick crystalline ice film (blue curve), and on bare $\mathrm{Pt}(111)$ (green curve). Isobutane was deposited at $30 \mathrm{~K}$ and the heating rate was $1 \mathrm{~K} / \mathrm{s}$. 
Fig. 8. TPD spectra for $1 \mathrm{ML}$ of isobutane deposited underneath of ASW thicknesses of 25 (black), 50 (red), 100 (blue), and $200 \mathrm{ML}$ (green). Isobutane and water were deposited at $30 \mathrm{~K}$ and the heating rate was $1 \mathrm{~K} / \mathrm{s}$. The peaks between 155 and $165 \mathrm{~K}$ labeled as "volcano peaks" are due to isobutane desorption that occurs during ASW crystallization. The "volcano" peak shifts to higher temperature with increasing overlayer thickness. The peaks between 170 and $185 \mathrm{~K}$ are labeled as "trapped peaks" and are due to isobutane desorption that occurs during the desorption of the ASW overlayer 
a)
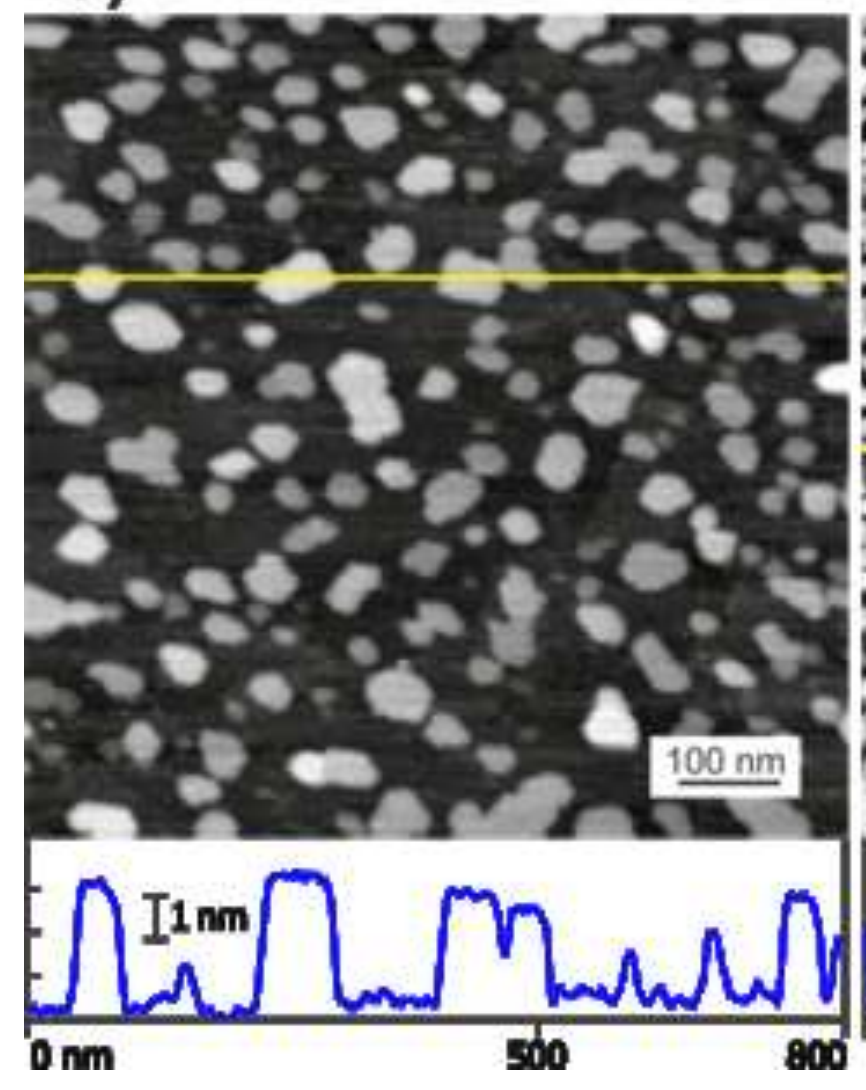

b)

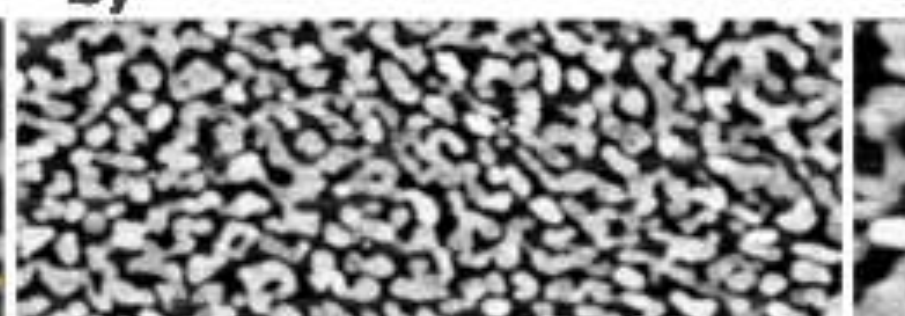

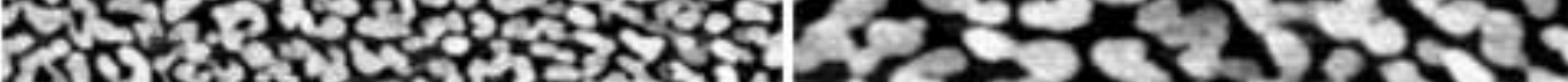

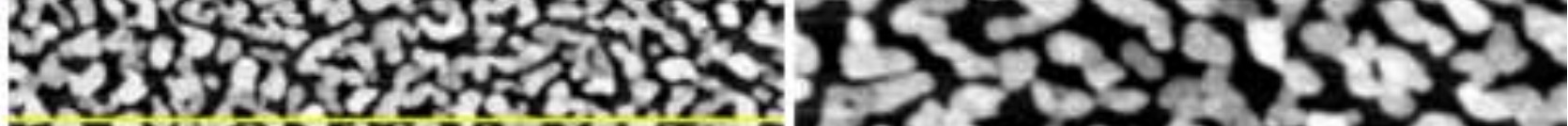
if.

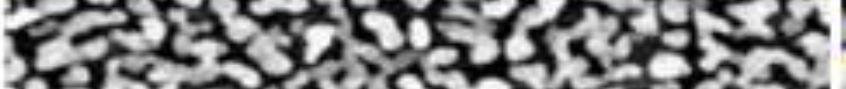

c)

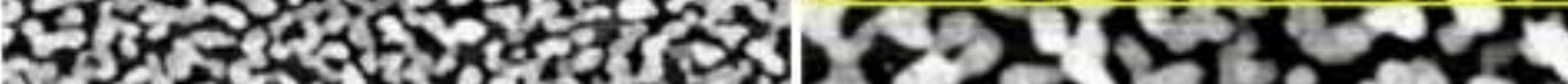

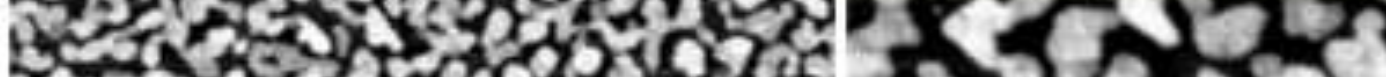
5 s.

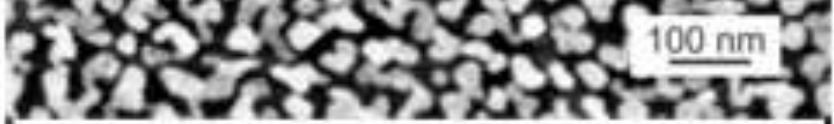
I1mm

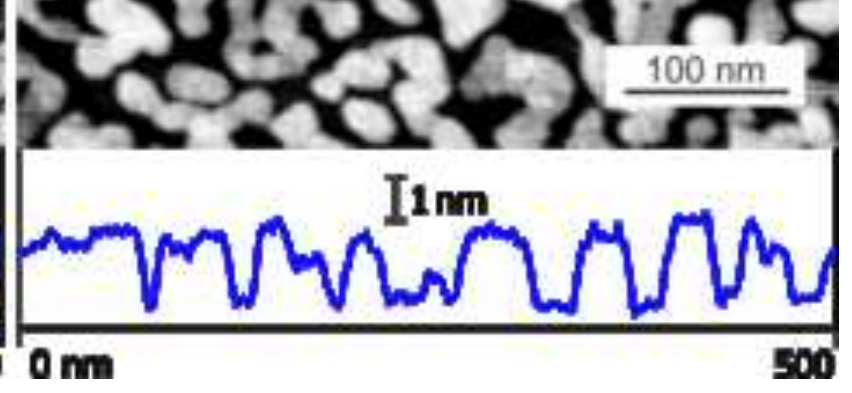


a)
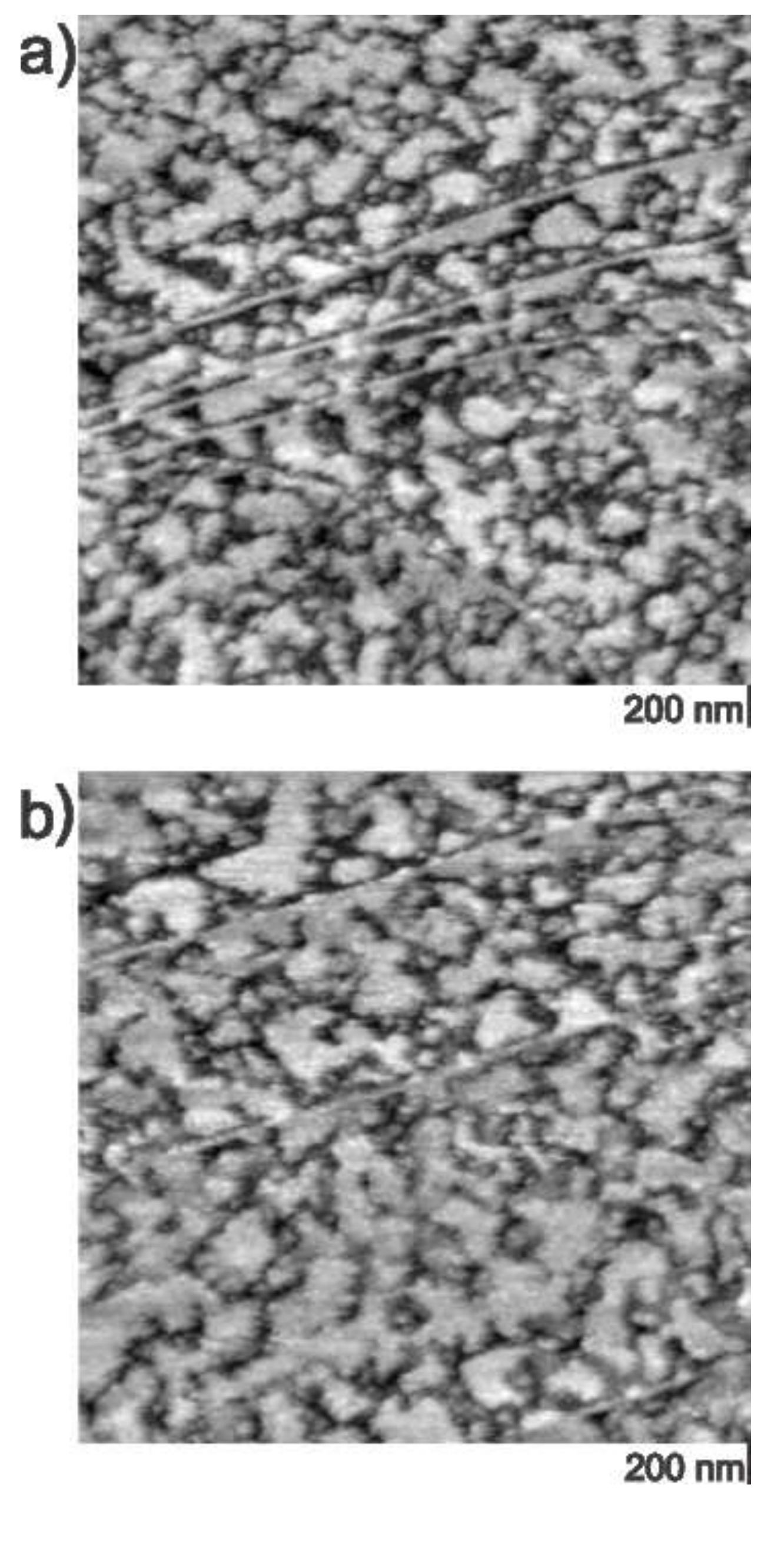

Figure (2)

s.

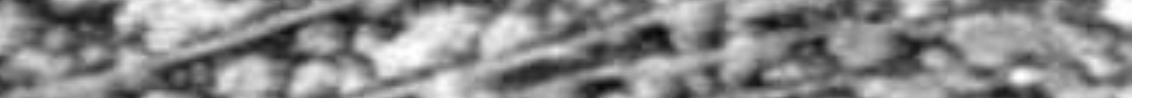

.

F.

.
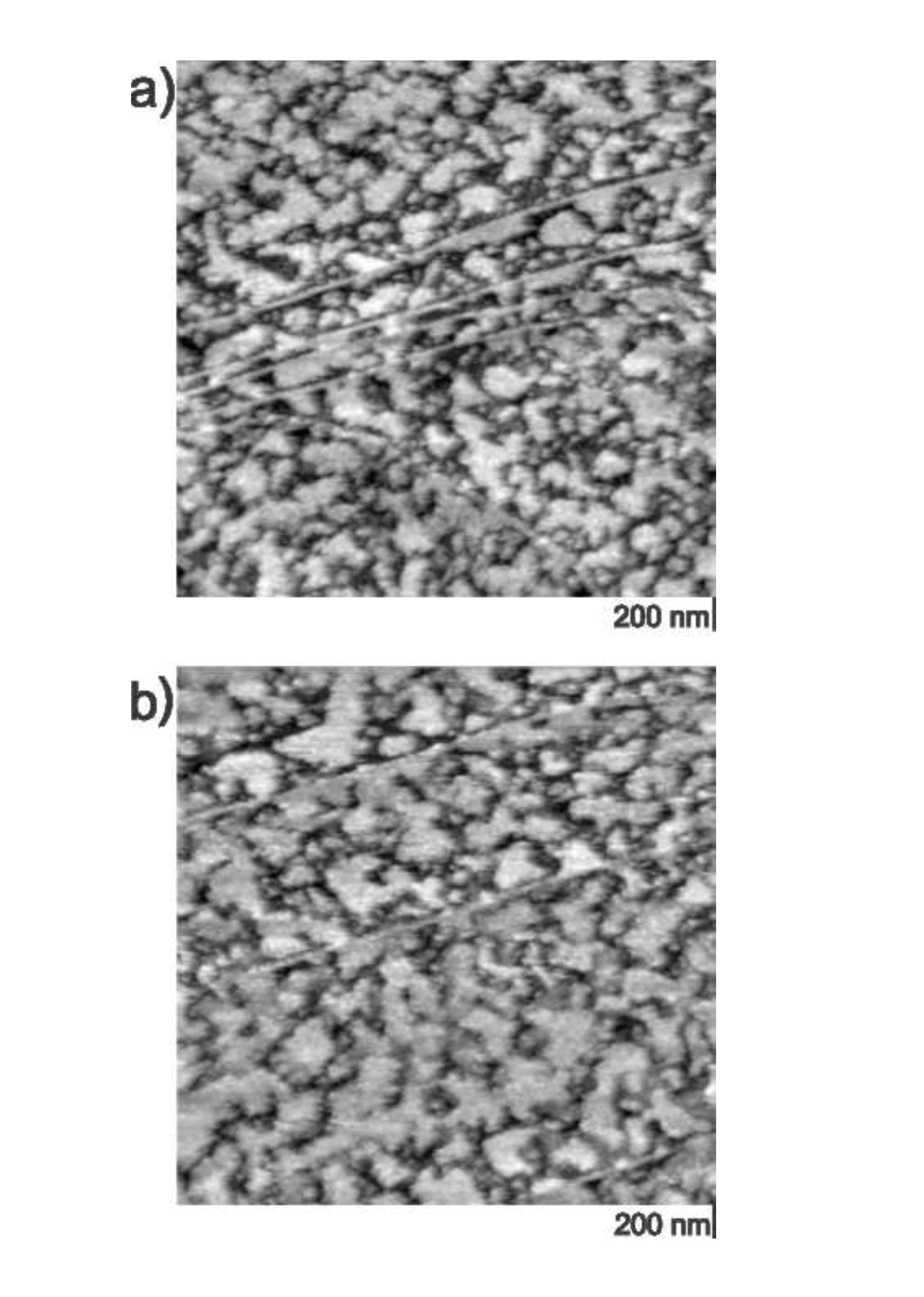

Figure

(1)

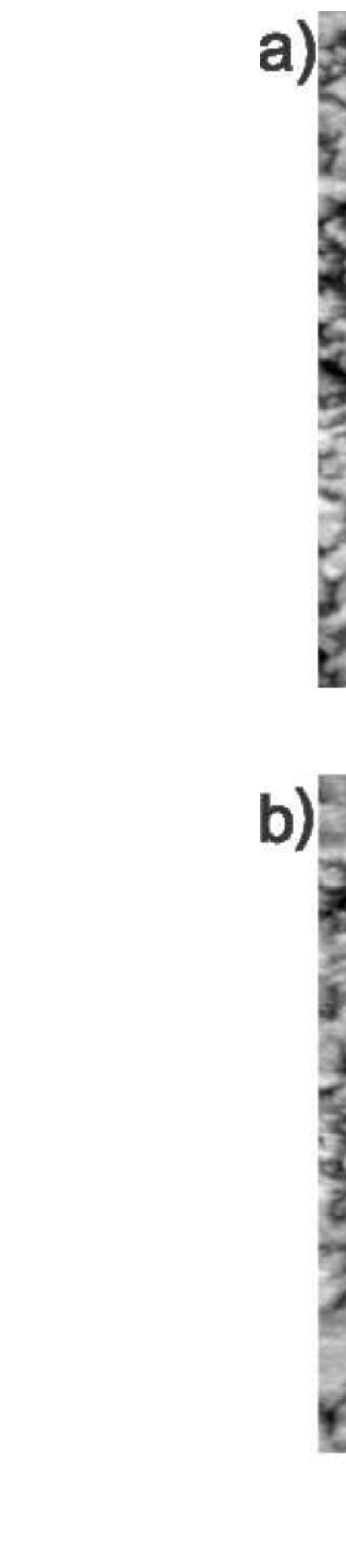




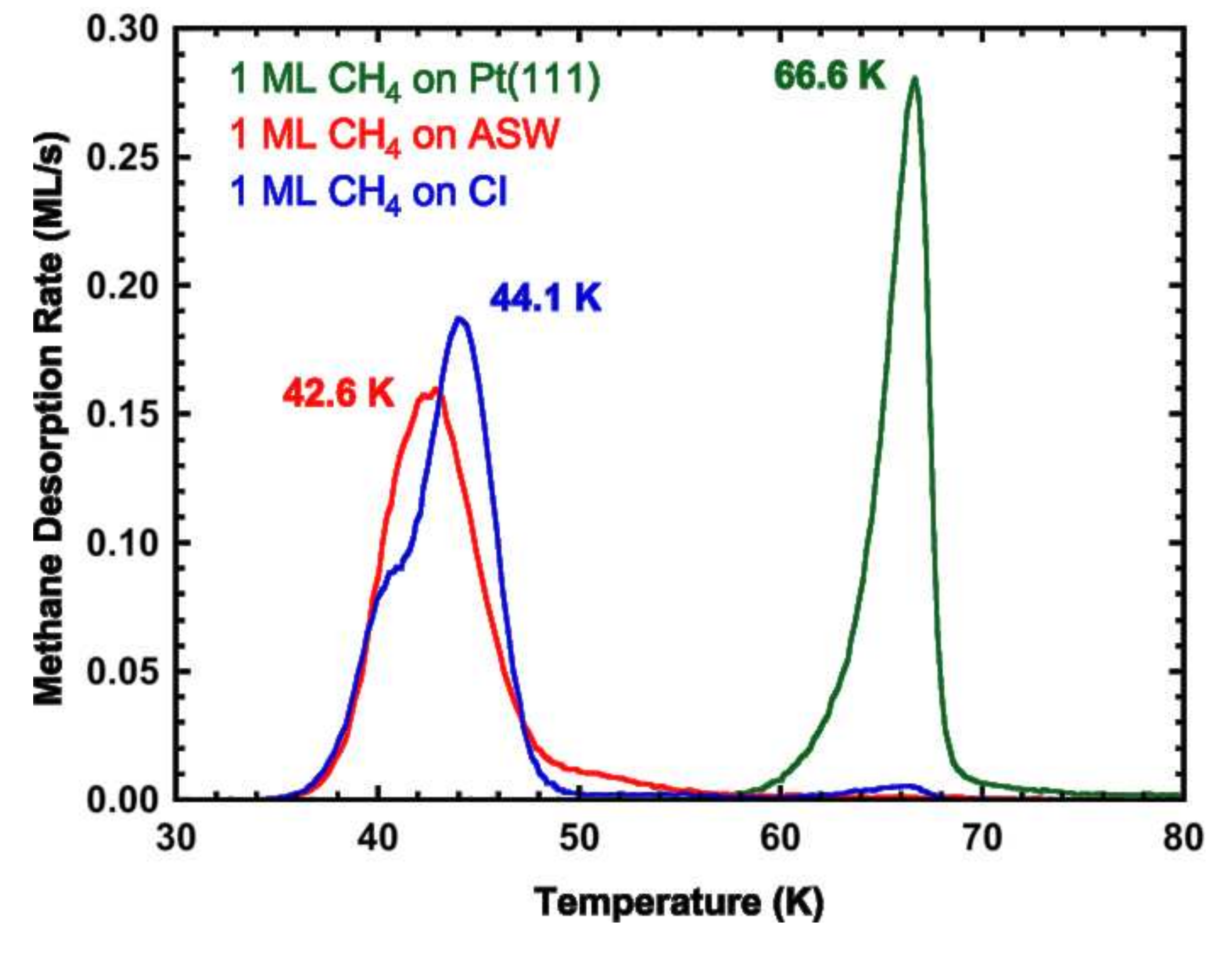


Figure 4

a)
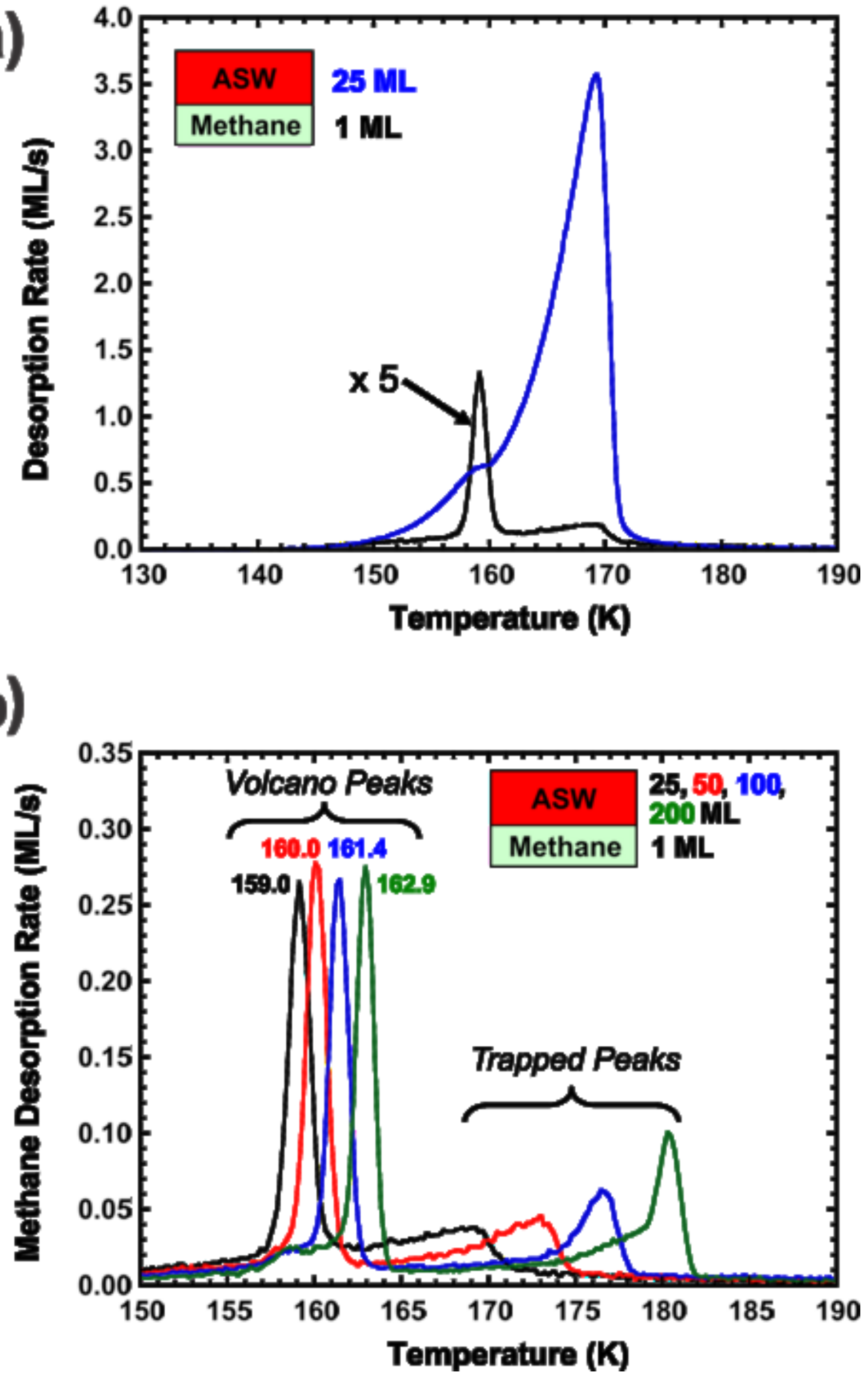
a)

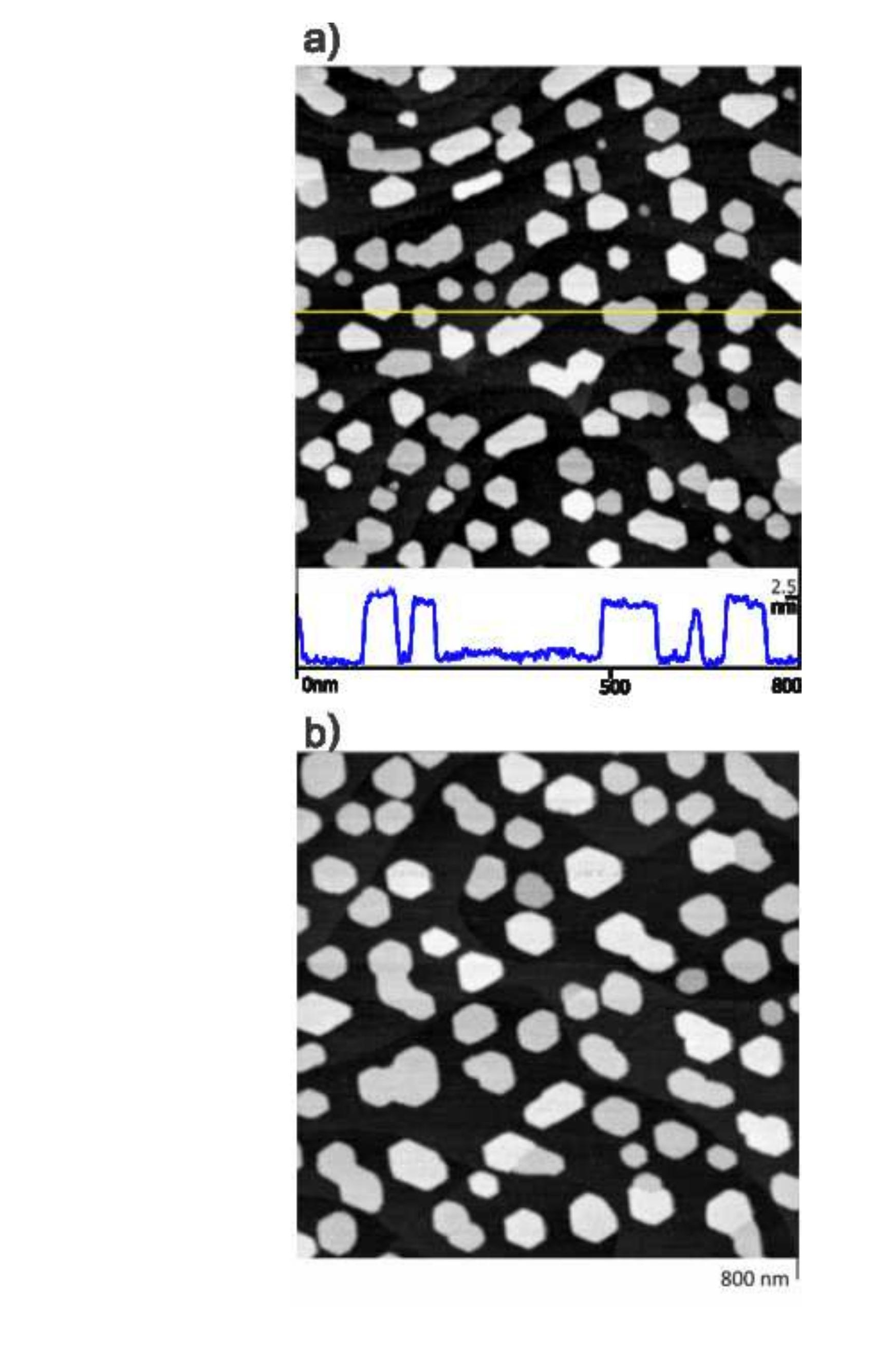

b)

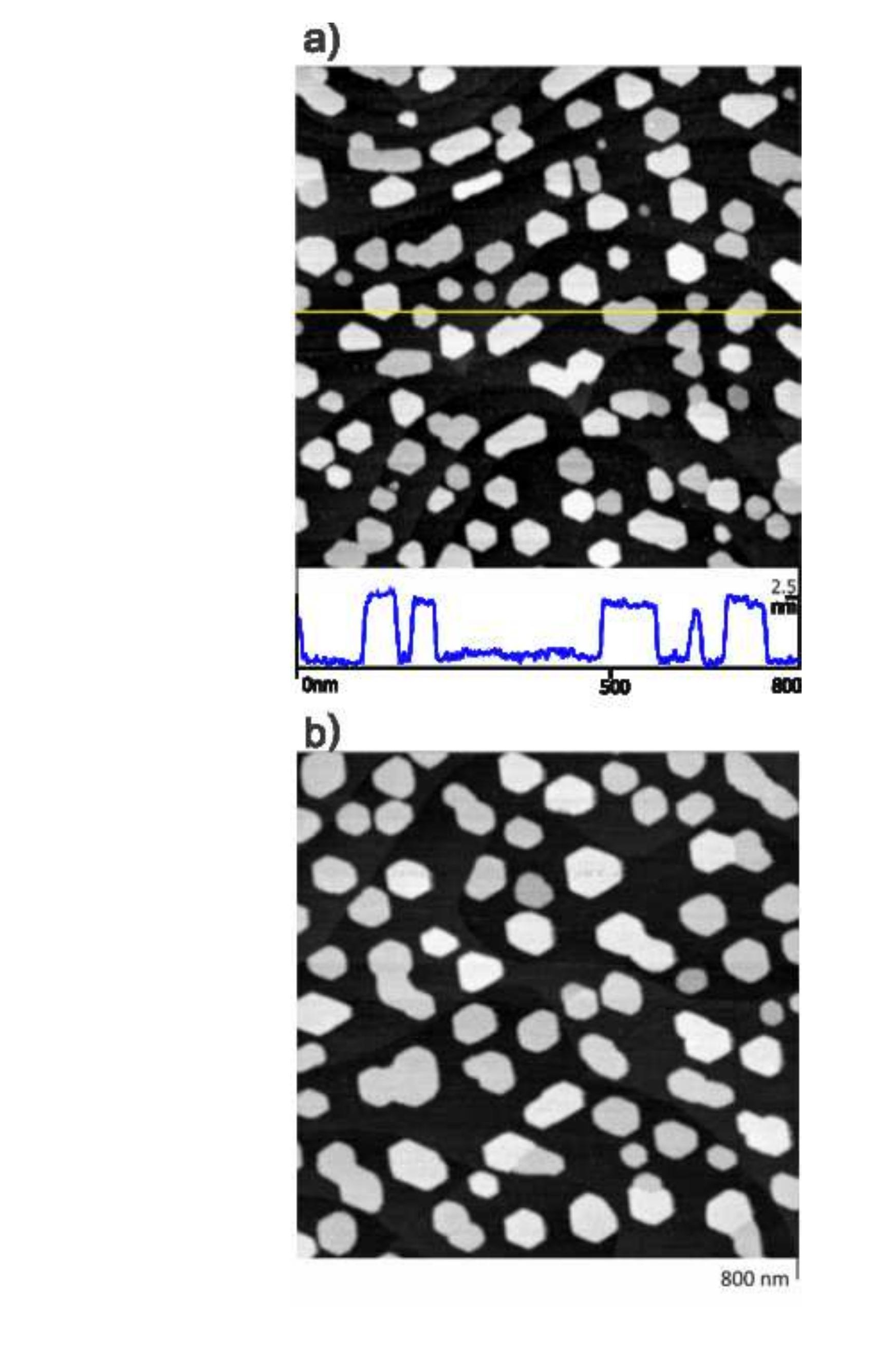

Figure 5

5

\section{0}

.



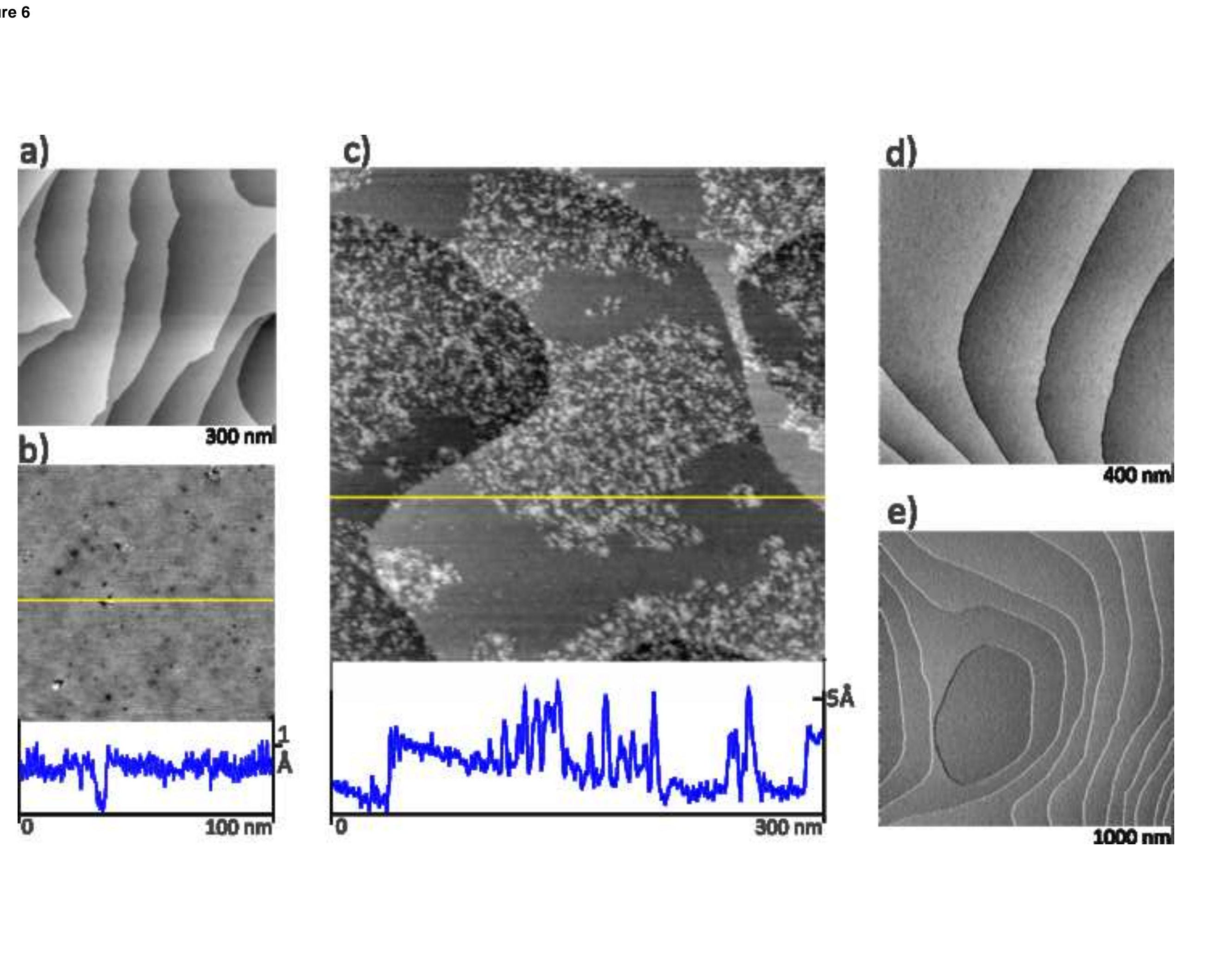

e)

.




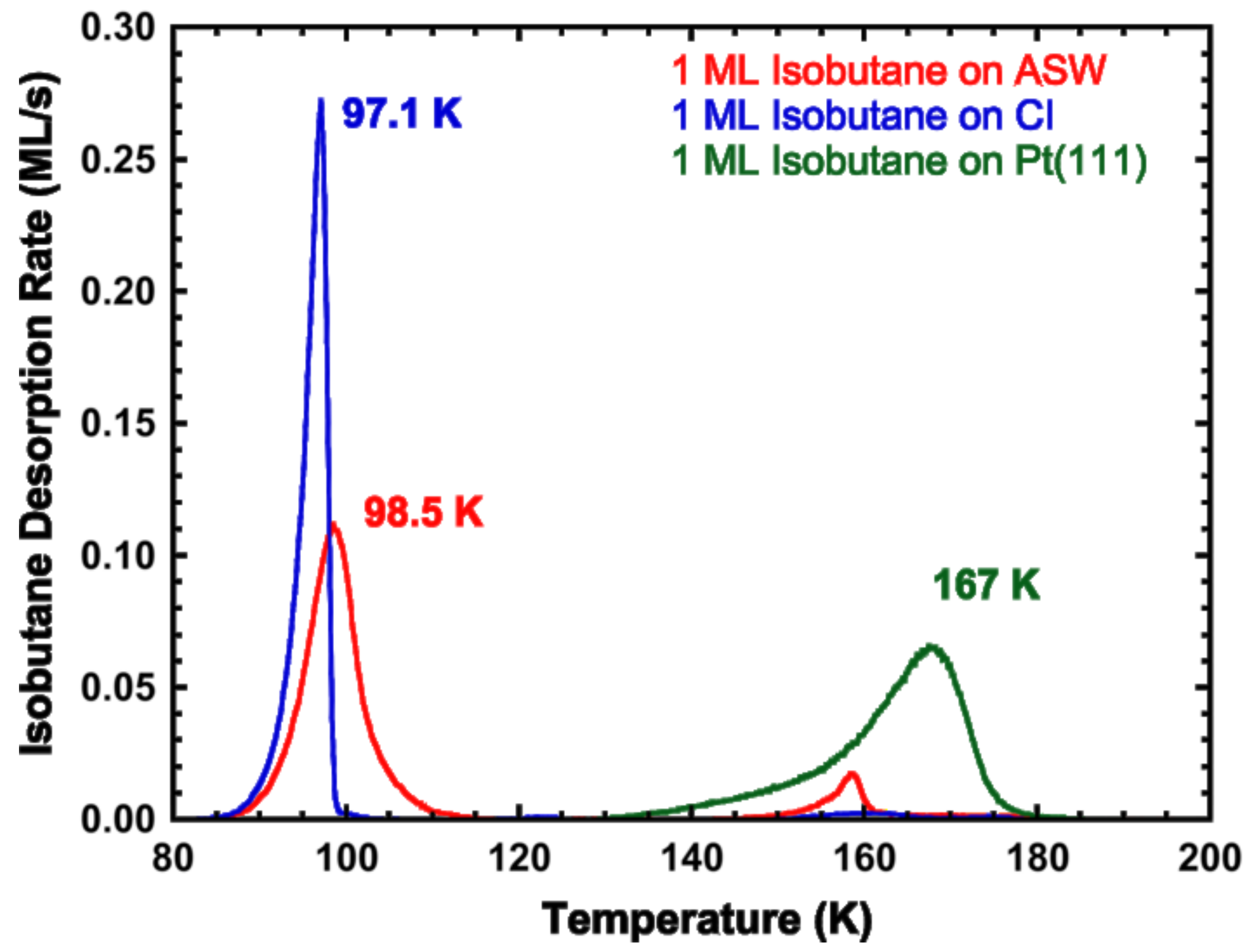




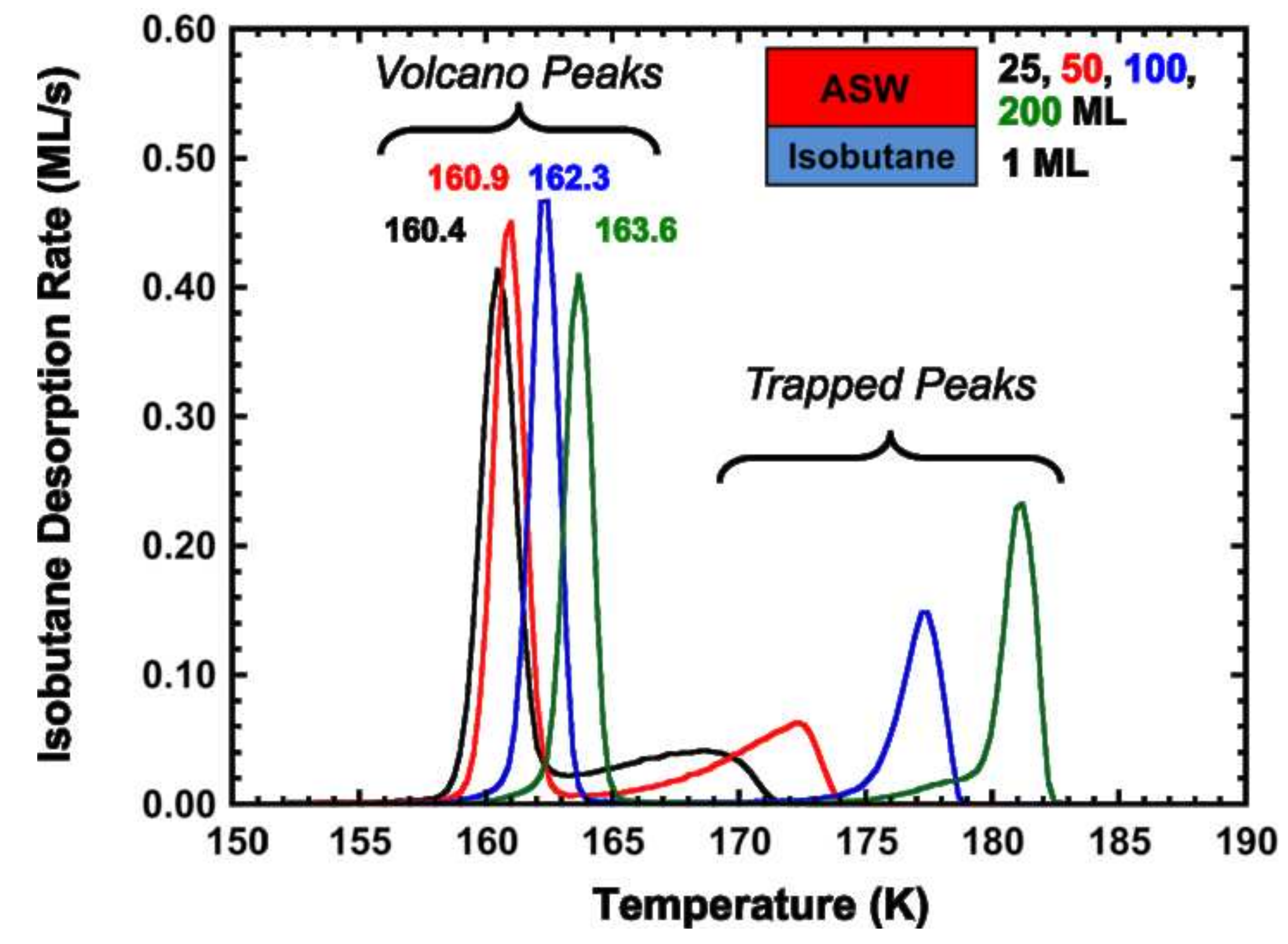



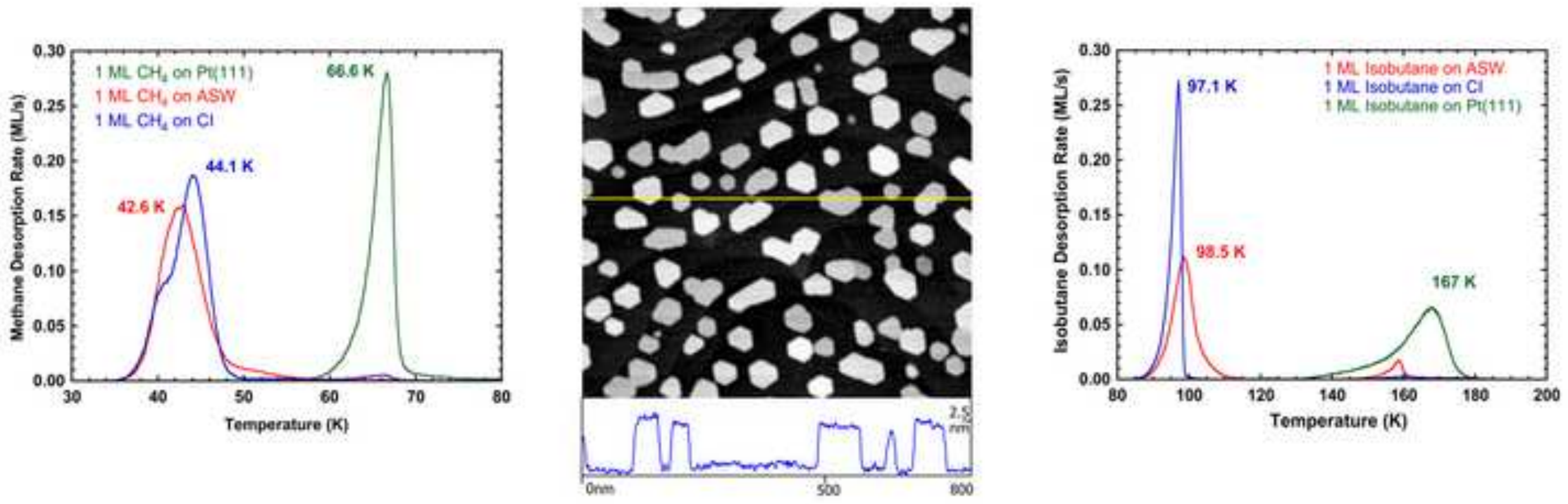